\title{
Research on Design Talent Training Model Based on the Internet Full Stack
}

\author{
Yuwei XU \\ Department of Artistic Design \\ Xiamen University Tan Kah Kee College \\ Zhangzhou, China
}

\begin{abstract}
Purpose: To inquire into training mode of internet designer. Method: Expanding the knowledge framework of student design and program based on the setting of integrated curriculum, and studying the training method of full stack designer, including thinking method of both design and engineer, and exploring advanced teaching method through flow program teaching, examining the students' master degree of knowledge with practical examination method. Conclusion: By the full stack talent training, the integrated quality of design talents can be enhanced, students' interdisciplinary problems encountered in their future work can be solved, so that the students may become the interdisciplinary talents in the direction of the Internet.
\end{abstract}

Keywords_Full Stack Designer; Design talents; Training mode; The Internet

The training of the internet designer is an important component of the development of the design education. The training of the visual designers at this stage has been able to meet the existing design requirements, but the training of the designer on internet is still in its infancy. Although internet design is a portion of visual design, it is required to master more professional knowledge besides design as design of internet direction is a synthetic discipline, a kind of interdisciplinary and comprehensive design talent is in need of training.

\section{DEMAND STATUS OF INTERNET TALENT}

According to the statistics of CNNIC2018 internet development status report, the size of Chinese netizens has reached 802 million people [1]. Along with the constant improvement of internet infrastructure, the digital strategy has been expounded systematically, the sustained penetration of internet service makes the size of netizens has been maintaining steady growth.1The escalation of netizens has facilitated the sustainable development of the internet industry. Due to the explosive development of internet enterprises over the recent years, the demand for talent has become an important conundrums for each corporation. As the gradual increase of design-driven enterprises, designer have been valued by enterprises, and internet design has become a hot profession.

Mobile application industry is a new pattern industry developed with the Internet, before that, there was no correlative design talent pool, and there was a lack of education system in area of expertise, and most talents are transformed from traditional visual designer. Accompanied by the advent of Internet dividends, large quantity of minitype start-up companies throw themselves into internet mobile industry, however, the consequent problem is the lack of the talents, and colleges and universities do not devote to the design content for the internet direction in personnel cultivating program, but only offer part of single elective courses to make up for the market demand.

Integrated talents in Internet design tendency are the key research orientation of design education. It is the imminent demand for developing integrated talents with internet interdisciplinary background. In effect, internet design still belongs to design category, but designers with backgrounds in computer, psychology, big data and data mining are required, such designers can not only be committed to the design field, but also understand the handling of programming and data processing, which can greatly enhance the communication and collaborative efficiency within the team and lower the operating costs of the corporation. Hence, it is so important to foster the comprehensive talented personnel for internet design.

\section{TRAINING OBJECTIVES AND EXPERIMENTAL TEACHING METHODS FOR ESTABLISHING FULL STACK DESIGNER}

\section{A. The Definition of Full Stack Designer}

Full Stack Designer refers to the designers who master a range of great skills in Internet products and are capable of completing the design and product exploitation independently, such as prototype design, visual design, front-end code, JS, etc. In order to enhance the iteration speed of the product in the internet product exploitation, small team agile development has been the normalcy, a smaller number of team can both guarantee the pace of product exploitation and reorient production at express speed. On account of the small number of people, the division of positions is not so explicit, while completing the design within the team, designers are also demanded to comprehend the corresponding knowledge of program development so as to maximum advantage in collaboration, this form of cooperation promotes the generation of full stack designers. But it does not mean that all the work has to be done by full stack designers alone, which means that the designer are needed to have a synthetic ways of thinking and be in consideration of the implementation and difficulty of the program in the design process so as to accurately control 
the process of product design, promote the quality of user experience, and decrease unnecessary rework in product development, making the whole development flow more unhindered. Full stack designers are not versatile designers, who can't substitute for the existence of engineers in teamwork, on the contrary, full stack designers can assist engineers to partially finish the work and reduce communication barriers in the process.

\section{B. Training Objective}

It is the goal of training talents of full stack design to cultivate designers of synectic thinking. Design thinking is a creative mode of thinking, aiming at a certain design task or a specific event, from the perspective of ultimate users, brand new solutions are sought through observation, interview, role playing and other forms. [2] Design thinking is a kind of stage creative thinking mode from a point to object, while integrated design thinking is a way of thinking that starts from the global situation of the product, through multiple perspectives and phases [3]. The training of full stack designers should begin from the T-shaped knowledge structure, and develop from horizontal and multi-domain to longitudinal design expertise, the two parts of which are the necessary stages of cultivating the knowledge structure of design talents.

\section{Experimental Teaching Exploration}

The workflow program teaching model of product design takes the workflow of product research, analysis, demand, interaction, design, front end and back end as the teaching procedure, whose main purpose is to enable students to understand the design and development procedure of Internet products, transform design thinking, as well as break through the traditional phased teaching mode.

Workflow is the process of splitting product design and manufacture into different stages and proceeding in sequence. Phased work is conducive to the development of industrialization, which can divide the work for cooperation, and greatly raise work efficiency. but there will always be inefficiencies and mismatches in the phase work connection, especially in the work of non-standardized products, uncontrollable factors can be increased with it. The design major is one of non-standardized industries, which is other than the factory assembly line production. Because it is required for design to produce results by conscious creativity, it shall be more aware of the level of collaboration in the workflow.

Experimental teaching of workflow program can improve the degree of coupling of periodic work, makes various stages have overlap, to reduce the problem of bridging between stages. For workflow program teaching, it requires teachers to have cross-disciplinary teaching capability, grasp knowledge in a variety of fields, and play a key link role in the whole process of teaching. In the teaching process, teachers ought to guide students to learn in the horizontal field independently, and through the workflow learning, expand the horizontal scope of knowledge, making experimental teaching truly achieve the goal of cultivating designers with comprehensive thinking.

\section{INNOVATIVE IDEAS OF COLLEGE CURRICULUM MODEL}

\section{A. Setting of Integrated Curriculum (To Set Up Design Courses with the Goal of Training Full Stack Designer)}

The course not only covers the design content, but also integrates the programming course (computer programming thinking) into the integrated curriculum. In the setting of integrated curriculum, the upstream and downstream domain knowledge of the work process should be taken into account, and the multidisciplinary curriculum setting enables students to master the subject knowledge before and after the design stage.

It is necessary to allow for the acceptability of design major students in the setting of integrated curriculum and follow the proper principles. Non-computer oriented students will encounter more difficulties in learning computer language, so teachers are required to get involved to guide them, thinking about the teaching method of computer language from the perspective of a designer, this is different from the previous computer teaching approach, which requires the teaching method of project demonstration and small function test.

To follow the basic law of teaching, the comprehensive curriculum can be set up in line with different grades of teaching content. In the lower grades, design is taken as the principal thing, and program is the auxiliary part, the course content can be set as the product functions with low difficulty and relatively easy to achieve. In the course process, it is necessary to emphasize the process of the integrated curriculum, so that students can understand the design content of the phase, and complete the revision of the current stage by connecting the content before and after the course. Through the overall stage learning, students can fundamentally master the basic thoughts of flow program teaching in the lower grades. In the curriculum setting of higher grades, the degree of difficulty in program implementation should be gradually increased, especially under the more complex cases, students should master the capacity to handle the integrated framework.

In the lateral curriculum setting, relatively simple front-end courses can be set at the early stage, such as HTML+CSS, JS, etc., as an entry-level computer course. As the front-end courses are easy to understand, they can be unfolded through the way of webpage elective courses, to make up for the deficiencies of the comprehensive courses. Using interface design to set basic display content and code to achieve effect enable students to complete the learning of the front-end code from smaller projects, which is beneficial to enhance students' confidence and convenient for their in-depth study.

\section{B. Curriculum Assessment Methods}

Practicalness assessment is taken as the main appraisal model. By examining students' realistic practical ability in the course, different from previous result-oriented check up forms, students' abilities to control projects and solve problems can be inspected with practice, so practice is a more accurate assessment method to inspect the program flow curriculum. For the practicality, it mainly examines students' ability to solve the periodic bridging problems and program errors encountered in the process curriculum. During the product development phase, project delays often occurs due to delivery 
process problems, through the investigation of stage bridging problem, it can be judged whether students have mastered the ability to solve problems in each stage in the process course. Errors often occur in programming, if the pure resultorientation is taken as the inspection form, it is unable to timely find whether the students have the ability to solve the error problem in the process. Therefore, during the investigation, students should be timely discovered and recorded to solve problems encountered by them, and through the analysis of the students encountered problems and solutions to determine whether they have mastered the ability to solve problems.

\section{FOCUSING ON THE TALENT TRAINING SYSTEM OF STUDENTS' INTEGRATING SKILLS}

\section{A. The Cross Setting of Basic Courses}

In the setting of foundation professional courses, part of engineering thinking method course can be set, by means of learning from different angles, the development and design thinking of Internet products can be comprehended [4] . Design direction students have had a mature training system in design thought and method, however, there is no corresponding training method for the thinking of engineers from the perspective of designers. Design thought is defined by IDEO, a design consultancy, as "to meet the rules of human demands that are both technically and commercially viable and can be transformed into customer value and market opportunity with the designer's perceptions and approaches." 3 While for the cultivation of talents with comprehensive skills, it needs comprehensive thinking from different perspectives, via the study from these two thinking perspectives, students can get hold of comprehensive thinking methods and lay a solid foundation for their comprehensive capability.

\section{B. The Seriation Guidance of Elective Courses}

Elective courses are usually supplementary to the trunk courses of the university, which can be selected according to students' preferences, but some of students' preferences are not conscious choices, but on the basis of the complexity of the course. In the setting of elective courses for comprehensive personnel training, the role of guiding function of series of elective courses shall be played on its own initiative, by the establishment of correlative elective courses, students can complete knowledge learning beyond the trunk courses through a series of elective courses, only to choose the direction of study, can students complete the course of this direction through a series of elective courses.

In the setting of elective courses, a stage setting is required, students are exposed to different learning contents in different stages, and the systematic and integrated learning is achieved by course orientation adjustment. Different from compulsory courses, students can choose the corresponding elective courses by adjusting the course direction, owing to the crossover nature of main courses, elective courses can connect with basic main courses, from which, different elective courses can be implemented to meet the knowledge demand of main courses.

\section{The Introduction of Real Online Projects}

Real project training is a cardinal and necessary process in talent cultivation [5]. Most course projects are proceeded on fictional projects, the setup approach of which has its has it's pros and cons, the advantage is that a project can be quickly conceived, and the disadvantage is that the real environments can't be accessed, especially in internet products, which is incapable to reflect the user's real demand without truthful data. The time requirement of real project should be taken into account in the introduction of real project, because for the project, there is the deadline required by the contract, which is different from the class ending time in the curriculum. The project deadline needs to be adjusted and tested before delivery, which will be confronted with the problem of course duration and project time, so in the course setting, it is needed to take into account the project schedule, and the formulation of course duration shall be in accordance with project time to satisfy the time requirements of the project. In the selection of the project, the element of the course duration is necessary to be considered, the project that meets course duration shall be selected as far as possible. Therefore, it is necessary to set flex time in the course setting to meet the time requirements of different projects [6].

\section{CONCLUSION}

It is still in a preliminary exploration stage for full stack design talent training in China, so it is a necessary phase to introduce the integrated curriculum into design system, however, it till needs to combine with the talent cultivation system of comprehensive skills, only this, can the closed loop of full stack design talent cultivation be formed. The cultivation of integrated design talents is a trend of university design development as well as the demand of the market for education. Through the discussion of the training mode of internet designer in this paper, and the analysis of training methods of full stack design talent, the students have mastered the other skills besides design, and can constantly improve their comprehensive and learning abilities via actual projects. In the full stack talent training, the teachers also need to improve their own quality to meet the requirements for comprehensive courses.

\section{REFERENCES}

[1] CNNIC. The 42nd China Statistical Report on Internet Development[R]. http://www.cnnic.net.cn/hlwfzyj/hlwxzbg/hlwtjbg/201808/P0201808206 30889299840.pdf. In Chinese

[2] YU Sui-huai, QU Min. New ideas of improving equipment manufacturing industry using design thinking. Journal of Machine Design. 2018,35(08),125-128. In Chinese

[3] BROWN T.Design thinking.Boston, MA:Harvard Business Review, 2008.

[4] Design Thinking. Why Design Thinking Works. Harvard Business Review. Sep/Oct2018, Vol. 96 Issue 5, p72-79. 8p.

[5] YANG ming-gang. Research on the deep integration path of teaching production under the new mode of network + education-based on the perspective of design talent training in five network education colleges in shanghai. Design. 2017,(22),111-113. In Chinese

[6] Han, Mengru, Yong, Y. The research and application of regional visual features application model based on visual design education. Agro Food Industry Hi Tech [1722-6996] Yong, Yang 2017, Vol. 28 Issue 3 , P1333 -1337 